\title{
Comparison of the effects of melatonin and genistein on radiation-induced nephrotoxicity: Results of an experimental study
}

\author{
EMINE CANYILMAZ ${ }^{1}$, GONCA HANEDAN USLU ${ }^{2}$, ZUMRUT BAHAT $^{1}$, MUSTAFA KANDAZ ${ }^{1}$, \\ SEVDEGUL MUNGAN $^{3}$, EMEL HACIISLAMOGLU $^{1}$, AHMET MENTESE $^{4}$ and ADNAN YONEY ${ }^{1}$ \\ ${ }^{1}$ Department of Radiation Oncology, Faculty of Medicine, Karadeniz Technical University, 61080 Trabzon; \\ ${ }^{2}$ Department of Radiation Oncology, Faculty of Medicine, Kanuni Research and Education Hospital, \\ 60080 Trabzon; Departments of ${ }^{3}$ Medical Pathology and ${ }^{4}$ Medical Biochemistry, Faculty of Medicine, \\ Karadeniz Technical University, 61080 Trabzon, Turkey
}

Received July 31, 2015; Accepted September 7, 2015

DOI: $10.3892 /$ br.2015.547

\begin{abstract}
The aim of the present study was to compare the effects of melatonin and genistein on radiation-induced nephrotoxicity (RIN). A total of 70 Swiss Albino mice were divided into 7 groups. Five control groups were defined, which were sham irradiation $(\mathrm{C}, \mathrm{G} 1)$, radiation therapy only (RT, $\mathrm{G} 2)$, melatonin (M, G3), genistein (G, G4) and polyethylene glycol-400 (G5), respectively. The co-treatment groups were the RT plus melatonin (RT+M, G6) and RT plus genistein $(\mathrm{RT}+\mathrm{G}, \mathrm{G} 7)$ groups. Irradiation was applied using a cobalt-60 teletherapy machine (80-cm fixed source-to-surface distance, $2.5-\mathrm{cm}$ depth). Melatonin was administered $(100 \mathrm{mg} / \mathrm{kg}$, intraperitoneal injection) $30 \mathrm{~min}$ before the single dose of irradiation, whereas genistein was administered $(200 \mathrm{mg} / \mathrm{kg}$, subcutaneous injection) 1 day before the single dose of irradiation. All the mice were sacrificed 6 months after irradiation. As an end point, the extent of renal tubular atrophy for each mouse was quantified with image analysis of histological sections of the kidney. Tissue malondialdehyde (MDA) levels were also measured in each animal. In the histopathological examination of the mouse kidneys, there was a statistically significant reduction $(\mathrm{P}<0.05)$ in the presence of tubular atrophy between the $\mathrm{RT}+\mathrm{M}$ and $\mathrm{RT}+\mathrm{G}$ groups and the RT group. There was a statistically significant increase in MDA levels in the irradiated versus sham groups (RT vs. C; $<<0.05$ ); however, MDA levels were significantly decreased by co-treatment with melatonin or genistein vs. $\mathrm{RT}$ alone $(\mathrm{RT}+\mathrm{M}$ and $\mathrm{RT}+\mathrm{G}$ vs. $\mathrm{RT}$; $\mathrm{P}<0.05)$. In conclusion, the present experimental study
\end{abstract}

Correspondence to: Dr Emine Canyilmaz, Department of Radiation Oncology, Faculty of Medicine, Karadeniz Technical University, 2 Farabi Street, 61080 Trabzon, Turkey

E-mail: dremocan@ktu.edu.tr

Key words: genistein, nephrotoxicity, melatonin, mice, radiation, radioprotection showed that melatonin and genistein supplementation prior to irradiation-protected mice against RIN, which may have therapeutic implications for radiation-induced injuries.

\section{Introduction}

Radiotherapy is one of the most common and important techniques for cancer treatment that is performed with the intent to cure, or for palliation $(1,2)$. The kidneys are radiosensitive organs. In patients with abdominal malignancies, such as gastric, pancreatic, lymphomas or any other abdominal neoplasms, irradiation of the kidneys is inevitable $(3,4)$. The radiation dose and irradiated volume are the limiting factors in abdominal radiotherapy and should be taken into consideration for the prevention of kidney injuries $(4,5)$. Radiation nephropathy includes increased vascular permeability, perfusion disturbance, inflammatory reactions and fibrosis $(3,4)$.

Melatonin ( $N$-acetyl-5-methoxytryptamine), an endogenous compound synthesized by the pineal gland in the human brain, was discovered $\sim 40$ years ago and reported to participate in the regulation of a number of physiological and pathological processes (6). Melatonin has a lipophilic nature, which allows the hormone to enter all the cells and subcellular compartments and establish high concentrations; melatonin also has the ability to cross morphophysiological barriers (7-9). Melatonin has been shown in several experimental and clinical conditions to have antioxidant and prophylactic properties against oxidative stress (10-15).

Genistein (4',5,7-trihydroxyisoflavone) has antioxidant and anti-inflammatory properties, low toxicity and is commonly used as a dietary supplement (16-18). The compound inhibits tyrosine kinase, possesses phytoestrogen activities, and protects against cerebral ischemia and skin injury by ultraviolet light $(19,20)$. Genistein has been reported to reduce acute lung injury from inflammation following lipopolysaccharide treatment (21); additionally, following whole-body irradiation, the administration of genistein in doses $\leq 400 \mathrm{mg} / \mathrm{kg}$ significantly increases survival without any toxicity (22). Of particular relevance, genistein is radioprotective for normal cells, while radiosensitizing toward 
a variety of cancer cells. With regards to the antioxidant, anti-inflammatory and anticancer properties of genistein, this compound has potential as a clinical therapeutic agent (20-23). However, little is known regarding the radioprotective role of genistein with respect to radiation-induced kidney injury.

Lipid peroxidation is an important cause of cell membrane destruction and damage, which is a likely contributing factor in the development of radiation-induced tissue damage $(24,25)$. An increase in malondialdehyde (MDA) levels is used as a marker of lipid peroxidation (26). During radiotherapy, melatonin pretreatment significantly reduces the level of MDA and increases the levels of enzymatic antioxidants in the ovaries and in plasma (27-30).

The present study was carried out to evaluate whether melatonin or genistein administration prior to irradiation would have a protective effect on radiation-induced nephrotoxicity (RIN) in an experimental mouse model.

\section{Materials and methods}

Study design. Swiss Albino mice (10-12-week-old, weighing $25 \pm 2 \mathrm{~g}$ ) were purchased from the Center for Laboratory Animals at the Karadeniz Technical University (Trabzon, Turkey). All the mice were acclimatized upon arrival, and representative animals were screened for evidence of disease. The Institutional Animal Care and Use Committee at Karadeniz Technical University approved the protocol used in the present study.

Animals were housed 4 per cage in a controlled animal holding room with a 12/12-h light/dark cycle; temperature and relative humidity were continually monitored to provide standard laboratory conditions. Food and water were provided ad libitum. Mice were divided into 7 groups composed of 10 animals. $\mathrm{C}$ was defined as the control group, and mice in this group were sham irradiated. RT was the radiation therapy only group. The M, G and PEG groups represented the melatonin, genistein and polyethylene glycol-400 (PEG-400) control groups, respectively. $\mathrm{RT}+\mathrm{M}$ and $\mathrm{RT}+\mathrm{G}$ represented the RT plus melatonin and RT plus genistein groups, respectively (Table I). Melatonin was administered $30 \mathrm{~min}$ before the RT, and genistein was administered $24 \mathrm{~h}$ before the RT. The two co-treatments were continued until the animals were sacrificed 24 weeks later. As an end point, the extent of renal tubular atrophy for each mouse was quantified with image analysis of histological sections of the kidney. Tissue MDA concentrations were also measured in each animal.

Irradiation protocol. Prior to whole-body irradiation, the animals were anesthetized with intraperitoneal (i.p.) injections of $90 \mathrm{mg} / \mathrm{kg}$ ketamine and $10 \mathrm{mg} / \mathrm{kg}$ xylazine. Subsequently, the animals were placed on a straphore in the prone position by taping their extremities. Correct positioning of the fields was controlled for each mouse via a therapy simulator. A 6-Gy single dose $\gamma$-radiation was selected according to previous studies $(31,32)$. Mice in the RT, RT+M and RT+G groups were irradiated with a Co60 teletherapy machine from a source-to-surface distance of $80 \mathrm{~cm}$. A single dose of $6 \mathrm{~Gy}$ $\gamma$-radiation was delivered to the whole-body area at a dose rate of $47.50 \mathrm{~Gy} / \mathrm{min}$. The dose was calculated for the central axis at a depth of $2.5 \mathrm{~cm}$.
Table I. Abbreviations used for the study groups.

\begin{tabular}{ll}
\hline Abbreviations & \multicolumn{1}{c}{ Study groups } \\
\hline C & Sham-irradiated control \\
RT & $6-$ Gy \\
M & Melatonin control \\
G & Genistein control \\
PEG & PEG-400 control \\
RT+M & 6 Gy + melatonin \\
RT+G & Gy + genistein
\end{tabular}

PEG-400, polyethylene glycol-400; RT, radiation therapy.

Melatonin and genistein protocols. For the mice in $\mathrm{M}$ and RT+M, melatonin (Melatonin Crystalline; Sigma-Aldrich, St. Louis, MO, USA) was prepared at a $1 \%$ concentration by dissolving in ethanol and diluting in $0.9 \%$ sodium chloride, and was administered at a dose of $100 \mathrm{mg} / \mathrm{kg}$ i.p. $30 \mathrm{~min}$ prior to exposure to radiation. The selection of a 30-min interval between the melatonin administration and exposure to radiation was based on 2 previous studies in animals $(33,34)$ and human volunteers (35).

Genistein and PEG, of molecular weight 400, were obtained from Sigma-Aldrich. Genistein was solubilized in PEG-400 on the day of the experiment using $20 \mathrm{sec}$ of sonication (Heat Systems-Ultrasonics Inc., Plainview, NY, USA). Genistein was administered at a dose of $100 \mathrm{mg} / \mathrm{kg}$ subcutaneously (s.c.) $24 \mathrm{~h}$ prior to being exposed to radiation. $0.9 \%$ sodium chloride was prepared at an equal volume with melatonin, and the remaining procedure was applied identically for $\mathrm{G}$ and $\mathrm{RT}+\mathrm{G}$ mice. PEG-400 was prepared at an equal volume with genistein, and the rest of the procedure was applied identically for group PEG mice. The selection of a 24-h interval between genistein administration and exposure to radiation was based on one earlier study in animals (20).

Determination of MDA activity. Kidney tissues were weighed and homogenized in ice-cold $1.15 \% \mathrm{KCl}(2$ and $10 \% \mathrm{w} / \mathrm{v}$, respectively). The homogenate was centrifuged at 2,000 $\mathrm{x}$ g for $10 \mathrm{~min}$. MDA levels in tissue samples were determined by the method of Mihara and Uchiyama (36). Tetramethoxypropane was used as a standard,and tissue MDA levels were calculated as $\mathrm{nmol} / \mathrm{g}$ wet tissue.

Morphological study and light microscopy. The animals were anesthetized and sacrificed by cervical dislocation 24 weeks after the start of irradiation. The kidneys were excised and fixed in a $10 \%$ formaldehyde solution and embedded in paraffin for light microscopic examination. One transverse section of each kidney was taken using vertical sections. The slices obtained were stained with hematoxylin and eosin to evaluate the fibrosis in the kidney. Tissues were also processed using a sirius red stain to examine for tubular atrophy. Kidney damage was scored based on the presence of tubular atrophy as none (0), light (1), moderate (2) or severe (3) damage. 
Table II. Tubular atrophy in the mice kidneys for each group of mice as examined by slit-lamp microscopy.

Tubular atrophy grade

\begin{tabular}{|c|c|c|c|c|c|}
\hline \multirow[b]{2}{*}{ Groups } & & \multirow[b]{2}{*}{ Total } \\
\hline & Absent & Grade 1 & Grade 2 & Grade 3 & \\
\hline Sham-irradiated control group (C) & 8 & 0 & 0 & 0 & 8 \\
\hline 6 Gy group (RT) & 0 & 4 & 2 & 4 & 10 \\
\hline Melatonin control group (M) & 4 & 4 & 0 & 0 & 8 \\
\hline Genistein control group (G) & 2 & 8 & 0 & 0 & 10 \\
\hline PEG-400 control group (PEG-400) & 0 & 2 & 3 & 1 & 6 \\
\hline $6 \mathrm{~Gy}+$ melatonin group $(\mathrm{RT}+\mathrm{M})$ & 2 & 6 & 0 & 0 & 8 \\
\hline 6 Gy+genistein group (RT+G) & 0 & 5 & 1 & 0 & 6 \\
\hline Total & 16 & 29 & 6 & 5 & 56 \\
\hline
\end{tabular}

PEG-400, polyethylene glycol-400; RT, radiation therapy.

Statistical analysis. Compatibility of the variables to normal distribution was investigated using visual (histogram and probability graphs) and analytical methods (one simple Kolmogorov-Smirnov test). The data are reported as mean \pm standard error and were analysed using one-way analysis of variance followed by a post hoc test for multiple comparisons. Type 1 errors of $<5 \%$ were accepted as statistically significant. All the statistical analyses were performed using SPSS version 13 (SPSS, Inc., Chicago, IL, USA).

\section{Results}

Histopathological examination of the mice kidneys. Glomerular and tubular structures were histopathologically normal in the $\mathrm{C}$ group (Fig. 1). Widespread kidney tubular atrophy and diffuse intertubular fibrosis were present in the RT group (Fig. 2). The rates, as assessed using slit-lamp biomicroscopy of grade 1, 2 and 3 tubular atrophy, respectively, in the $\mathrm{C}(0,0$ and $0 \%)$, PEG $(33.3,50$ and $16.7 \%),, \mathrm{M}(50$, 0 and $0 \%,), \mathrm{G}(80,0$ and $0 \%), \mathrm{RT}(40,20$ and $40 \%), \mathrm{RT}+\mathrm{M}(75$, 0 and $0 \%)$ and $\mathrm{RT}+\mathrm{G}$ groups $(83.3,16.7$ and $0 \%)$ are presented in Table II.

In the histopathological examination of the mice kidneys, there was a statistically significant elevation of tubular atrophy induced by $\gamma$-irradiation (C vs. RT; P $<0.05$; Table III). A significant elevation in all the investigated histopathological parameters was identified in the $P E G$ and $R T+G$ groups versus the $\mathrm{C}$ group $(\mathrm{P}<0.05)$ but not between the $\mathrm{M}, \mathrm{G}$ and $\mathrm{RT}+\mathrm{M}$ groups versus the $\mathrm{C}$ group $(\mathrm{P}>0.05)$. In addition, $\mathrm{a}$ significant elevation was observed in all the investigated histopathological parameters in the RT group compared to the $\mathrm{M}$, $\mathrm{G}, \mathrm{RT}+\mathrm{M}$ and $\mathrm{RT}+\mathrm{G}$ groups $(\mathrm{P}<0.05)$ but not the $\mathrm{PEG}$ group $(\mathrm{P}>0.05)$, indicating reduced injury in the irradiation plus co-treatment groups. However, there was no statistically significant difference between the $\mathrm{RT}+\mathrm{M}$ and the $\mathrm{RT}+\mathrm{G}$ groups $(\mathrm{P}>0.05)$. At the end of the histological examination, all the mice in each group had a certain degree of tubular atrophy.

Changes in MDA level following irradiation. Whole-body irradiation by 6 Gy of $\gamma$-irradiation, as a single dose, significantly increased the MDA level $(\mathrm{P}<0.05)$ in the mice kidneys

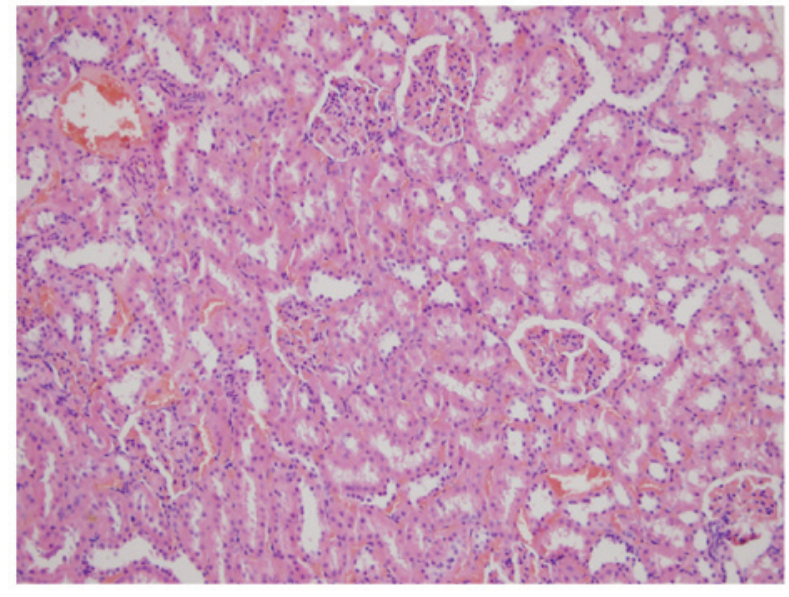

Figure 1. In the control group, glomerular and tubular structures were observed to be histopathologically normal (hematoxylin and eosin; magnification, x50).

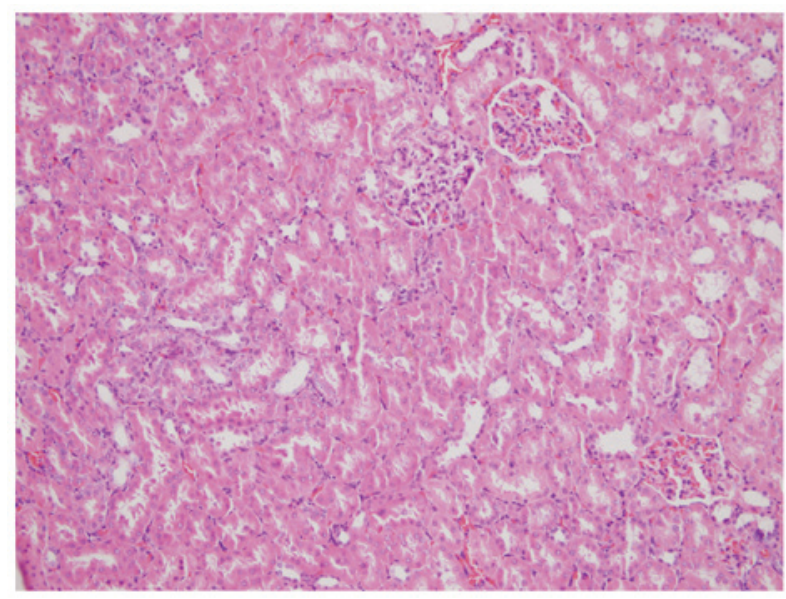

Figure 2. Renal tubular atrophy and diffuse intertubular fibrosis in the radiation therapy group (hematoxylin and eosin; magnification, x50).

when compared to the untreated controls (RT vs. C; Table IV). Melatonin and genistein supplementation in conjunction with body irradiation significantly decreased the MDA level in the 
Table III. Mean value of tubular atrophy for each group of mice.

\begin{tabular}{ll}
\hline Groups & $\begin{array}{l}\text { Mean tubular } \\
\text { atrophy value }\end{array}$ \\
\hline Sham-irradiated control group (C) & $0.12 \pm 0.35^{\text {b,e, }}$ \\
6-Gy group (RT) & $2.00 \pm 0.94^{\mathrm{a}, \mathrm{c}, \mathrm{d}, \mathrm{f}, \mathrm{g}}$ \\
Melatonin control group (M) & $0.50 \pm 0.53^{\mathrm{b}, \mathrm{e}}$ \\
Genistein control group (G) & $0.80 \pm 0.42^{\mathrm{b}, \mathrm{e}}$ \\
PEG-400 control group (PEG-400) & $1.83 \pm 0.75^{\mathrm{a}, \mathrm{c}, \mathrm{d}, \mathrm{f}, \mathrm{g}}$ \\
6 Gy+melatonin group (RT+M) & $0.75 \pm 0.46^{\mathrm{b}, \mathrm{e}}$ \\
6 Gy+genistein group (RT+G) & $1.16 \pm 0.40^{\mathrm{a}, \mathrm{b}, \mathrm{e}}$ \\
\hline
\end{tabular}

PEG-400, polyethylene glycol-400; RT, radiation therapy. Values are presented as mean \pm standard error for 7 mice in each group. $\mathrm{P}<0.05$ compared to ${ }^{\mathrm{a}} \mathrm{C}$; ${ }^{\mathrm{b}} \mathrm{RT} ;{ }^{\mathrm{c}} \mathrm{M} ;{ }^{\mathrm{d}} \mathrm{G} ;{ }^{\mathrm{e}} \mathrm{PEG}$; ${ }^{\mathrm{f}} \mathrm{RT}+\mathrm{M} ;{ }^{\mathrm{g}} \mathrm{RT}+\mathrm{G}$.

Table IV. Level of MDA in the mice kidneys.

Groups

Mean MDA value,

\begin{tabular}{ll}
\hline Sham-irradiated control group (C) & $37.3 \pm 1.11^{\mathrm{b},}$ \\
6-Gy group (RT) & $45.6 \pm 0.90^{\mathrm{a}, \mathrm{c}, \mathrm{d}, \mathrm{f}, \mathrm{g}}$ \\
Melatonin control group (M) & $40.4 \pm 1.00^{\mathrm{b}}$ \\
Genistein control group (G) & $35.2 \pm 0.94^{\mathrm{b}}$ \\
PEG-400 control group (PEG-400) & $38.5 \pm 1.28^{\mathrm{b}}$ \\
6 Gy+melatonin group (RT+M) & $37.5 \pm 1.17^{\mathrm{b}}$ \\
6 Gy+genistein group (RT+G) & $39.1 \pm 0.75^{\mathrm{b}}$ \\
\hline
\end{tabular}

MDA, malondialdehyde; PEG-400, polyethylene glycol-400; RT, radiation therapy. Values are presented as mean \pm standard error for 7 mice in each group. $\mathrm{P}<0.05$ compared to ${ }^{\mathrm{a}} \mathrm{C}$; ${ }^{\mathrm{b}} \mathrm{RT}$; ${ }^{\mathrm{c}} \mathrm{M}$; ${ }^{\mathrm{d}} \mathrm{G}$; ${ }^{\mathrm{e}} \mathrm{PEG}$; ${ }^{\mathrm{f}} \mathrm{RT}+\mathrm{M} ;{ }^{\mathrm{g}} \mathrm{RT}+\mathrm{G}$.

kidney (RT vs. RT+M and RT vs. RT+G; P<0.05), but there was no statistically significant difference between the co-treatment groups ( $\mathrm{RT}+\mathrm{M}$ vs. $\mathrm{RT}+\mathrm{G} ; \mathrm{P}>0.05)$.

\section{Discussion}

In numerous clinical and experimental studies, kidneys have been shown to be highly sensitive to radiation injuries (1). Radiation nephropathy presents itself in $20 \%$ of patients following irradiation; the clinical presentations include acute radiation nephritis, chronic radiation nephritis, malignant hypertension and benign hypertension (37). Clinical signs of radiation damage that develop after a period of 4-12 months are of particular concern (3,38-40). In the kidney, irradiation leads to a progressive reduction in function associated with concomitant glomerulosclerosis and/or tubulointerstitial fibrosis, which largely depends on the total radiation dose, dose per fraction, irradiated volume and age at the time of irradiation (3).

Melatonin is a highly efficient free radical scavenger and general antioxidant that protects DNA, lipids and proteins (12-15). The radioprotective effect of melatonin was confirmed in in vitro $(41,42)$ and in vivo studies $(4,36)$, as well as when administered to humans $(42,43)$, mainly by assessing the induction of chromosomal aberration and micronucleus in cultured lymphocytes. Several studies have demonstrated that melatonin appears to ameliorate irradiation-induced injury in various organs including the spleen $(44,45)$, liver (29), lung, colon, ileum (46), kidney (37), lens (47), spinal cord (48) and brain (49). Doses of melatonin in mice, $10-250 \mathrm{mg} / \mathrm{kg}$, have been tested in in vivo investigations (4). In the present study, $100 \mathrm{mg} / \mathrm{kg}$ melatonin was administered by i.p. injection in accordance with the literature.

Genistein has antioxidant and anti-inflammatory properties, has low toxicity and is commonly used as a dietary supplement $(16,50)$. Wei et al (51) reported that genistein provided protection against non-ionizing ultraviolet-B radiation through either direct quenching of reactive oxygen species (ROS) or indirect anti-inflammatory effects when it was applied to the skin of hairless mice $1 \mathrm{~h}$ before exposure. Genistein also reduced the frequency of micronucleated reticulocytes in the peripheral blood of mice receiving a sublethal dose of ionizing radiation (52). Thus, the antioxidant activity of genistein and its ability to protect against radiation-induced cytogenetic damage could contribute to its radioprotective action. Landauer et al (20) demonstrated in a preliminary study that oral administration of pharmacological doses of genistein is radioprotective in adult mice. However, oral administration required a multiple dosing regimen beginning several days prior to irradiation. The beneficial effects of single-dose s.c. administered radioprotectants are also being evaluated in the clinic in conjunction with RT (53). The study by Landauer et al (20) reported the results of experiments designed to assess in vivo radioprotection in whole-body $\gamma$-irradiated mice with genistein. Radioprotection was demonstrated without the toxicity or performance-degrading side effects in mice receiving a single s.c. administration of genistein. Therefore, the present study administered genistein at $100 \mathrm{mg} / \mathrm{kg}$ s.c. in accordance with the literature.

Tubular interstitial injury is an additional feature of radiation nephropathy. Morphological and physiological studies have identified the renal tubule system as the site of maximum radiation damage $(1,38,54,55)$. The results of the present study indicated that the tubular toxicity induced by 6 Gy irradiation became apparent during the 6 -month period after radiation exposure. The differences observed during histopathological evaluation were statistically significant. The degrees of grades 2 and 3 tubular atrophy were 20 and $40 \%$, respectively, for the RT controls. Treatment with RT+M blocked all grade 2 and 3 tubular atrophy, and RT+G treatment blocked all grade 3 and some grade 2 atrophy (16.7\%). These results indicate that pretreatment with melatonin and genistein markedly decreased the severity of tubular changes that occurred following irradiation.

The present results with supplemental melatonin are in agreement with the published literature on the antioxidant effects of melatonin. Melatonin administration prior to total body irradiation with a single dose of 6 Gy prevents rat liver damage induced by irradiation, reflecting the antioxidant roles of melatonin against $\gamma$-irradiation-induced oxidative damage (29). The liver tissue MDA levels in irradiated rats that were pretreated with melatonin ( 5 or $10 \mathrm{mg} / \mathrm{kg}$ ) were 
significantly decreased, while the superoxide dismutase and glutathione peroxidase activities were significantly increased. Similarly, the levels of mouse kidney MDA in the $\gamma$-irradiation-plus $100 \mathrm{mg} / \mathrm{kg}$ melatonin (RT+M) group were significantly decreased when compared with the $\gamma$-irradiation-only (RT) group.

Genistein has stronger antioxidative properties combined with its capacity to activate the antioxidant systems; the resulting reduction of free radical lipid peroxidation protects and stabilizes the cellular membrane structure (50). Genistein protects against ultraviolet-B radiation either by directly quenching ROS or by indirect anti-inflammatory effects when applied to the skin of hairless mice prior to radiation exposure (51). Kim et al (56) demonstrated that genistein can significantly protect against a radiation-induced increase of ROS in the testis, suggesting that genistein protects against testicular injury from radiation via a protective mechanism that includes antioxidative activity. In agreement with the published literature on the radioprotective and antioxidant effects of genistein in the skin and tests, the levels of kidney MDA in the $\gamma$-irradiation-plus $100 \mathrm{mg} / \mathrm{kg}$ genistein $(\mathrm{RT}+\mathrm{G})$ group were significantly decreased when compared with the $\gamma$-irradiation-only (RT) group.

In conclusion, melatonin and genistein have clear antioxidant properties and are likely to be valuable adjuvant drugs for the protection against $\gamma$-irradiation and/or use as antioxidants against oxidative stress. Light microscopic examinations and MDA measurement performed at the end of the 6-month follow-up period revealed that the kidneys of the mice in the $\mathrm{RT}+\mathrm{M}$ and $\mathrm{RT}+\mathrm{G}$ groups were healthier compared with the radiotherapy only group mice. Based on the present findings, additional studies of the protective effects of melatonin and genistein against RIN are merited.

\section{References}

1. Robbins ME and Bonsib SM: Radiation nephropathy: A review. Scanning Microsc 9: 535-560, 1995.

2. Bolling T, Schuck A, Rube C, Hesselmann S, Pape H, Dieckmann K, Pollinger B, Kortmann RD, Speiser-Held I, Meyer FM, et al: Therapy-associated late effects after irradiation of malignant diseases in childhood and adolescence. Feasibility analyses of a prospective multicenter register study. Strahlenther Onkol 182: 443-449, 2006 (In German).

3. Cohen EP and Robbins ME: Radiation nephropathy. Semin Nephrol 23: 486-499, 2003.

4. Vijayalaxmi, Meltz ML, Reiter RJ, Herman TS and Kumar KS: Melatonin and protection from whole-body irradiation: Survival studies in mice. Mutat Res 425: 21-27, 1999.

5. El-Missiry MA: Prophylactic effect of melatonin on lead-induced inhibition of heme biosynthesis and deterioration of antioxidant system in male rats. J Biochem Mol Toxicol 14: 57-62, 2000 .

6. El-Missiry MA and Abd El-Aziz AF: Influence of melatonin on proliferation and antioxidant system in Ehrlich ascites carcinoma cells. Cancer Lett 151: 119-125, 2000.

7. Shirazi A, Ghobadi G and Ghazi-Khansari M: A radiobiological review on melatonin: A novel radioprotector. J Radiat Res (Tokyo) 48: 263-272, 2007.

8. Vijayalaxmi, Reiter RJ, Tan DX, Herman TS and Thomas CR Jr: Melatonin as a radioprotective agent: A review. Int J Radiat Oncol Biol Phys 59: 639-653, 2004.

9. Reiter RJ, Tan DX, Cabrera J, D'Arpa D, Sainz RM, Mayo JC and Ramos S: The oxidant/antioxidant network: Role of melatonin. Biol Signals Recept 8: 56-63, 1999.

10. Othman AI,El-Missiry MA and Amer MA: The protective action of melatonin on indomethacin-induced gastric and testicular oxidative stress in rats. Redox Rep 6: 173-177, 2001.
11. Othman AI, al Sharawy S and el-Missiry MA: Role of melatonin in ameliorating lead induced haematotoxicity. Pharmacol Res 50: 301-307, 2004

12. Reiter RJ, Tan DX, Manchester LC and Qi W: Biochemical reactivity of melatonin with reactive oxygen and nitrogen species: A review of the evidence. Cell Biochem Biophys 34: 237-256, 2001.

13. Reiter RJ, Tan DX, Gitto E, Sainz RM, Mayo JC, Leon J, Manchester LC, Vijayalaxmi, Kilic E and Kilic U: Pharmacological utility of melatonin in reducing oxidative cellular and molecular damage. Pol J Pharmacol 56: 159-170, 2004.

14. Kaya H, Delibas N, Serteser M, Ulukaya E and Ozkaya O: The effect of melatonin on lipid peroxidation during radiotherapy in female rats. Strahlenther Onkol 175: 285-288, 1999.

15. Reiter RJ, Tan DX, Osuna C and Gitto E: Actions of melatonin in the reduction of oxidative stress. A review. J Biomed Sci 7: 444-458, 2000

16. Kruk I, Aboul-Enein HY, Michalska T, Lichszteld K and Kladna A: Scavenging of reactive oxygen species by the plant phenols genistein and oleuropein. Luminescence 20: 81-89, 2005.

17. Weiss JF and Landauer MR: Radioprotection by antioxidants. Ann N Y Acad Sci 899: 44-60, 2000.

18. Liang HW, Qiu SF, Shen J, Sun LN, Wang JY, Bruce IC and Xia Q: Genistein attenuates oxidative stress and neuronal damage following transient global cerebral ischemia in rat hippocampus. Neurosci Lett 438: 116-120, 2008.

19. Kang JL, Lee HW, Lee HS, Pack IS, Castranova V and Koh Y: Time course for inhibition of lipopolysaccharide-induced lung injury by genistein: Relationship to alteration in nuclear factor-kappaB activity and inflammatory agents. Crit Care Med 31: 517-524, 2003.

20. Landauer MR, Srinivasan V and Seed TM: Genistein treatment protects mice from ionizing radiation injury. J Appl Toxicol 23: 379-385, 2003.

21. Davis TA, Mungunsukh O, Zins S, Day RM and Landauer MR: Genistein induces radioprotection by hematopoietic stem cell quiescence. Int J Radiat Biol 84: 713-726, 2008.

22. Hillman GG, Wang Y, Kucuk O, Che M, Doerge DR, Yudelev M, Joiner MC, Marples B, Forman JD and Sarkar FH: Genistein potentiates inhibition of tumor growth by radiation in a prostate cancer orthotopic model. Mol Cancer Ther 3: 1271-1279, 2004.

23. Raffoul JJ, Wang Y, Kucuk O, Forman JD, Sarkar FH and Hillman GG: Genistein inhibits radiation-induced activation of NF-kappaB in prostate cancer cells promoting apoptosis and G2/M cell cycle arrest. BMC Cancer 6: 107, 2006.

24. Valko M, Rhodes CJ, Moncol J, Izakovic M and Mazur M: Free radicals, metals and antioxidants in oxidative stress-induced cancer. Chem Biol Interact 160: 1-40, 2006.

25. Riley PA: Free radicals in biology: Oxidative stress and the effects of ionizing radiation. Int J Radiat Biol 65: 27-33, 1994.

26. Kleinman WA and Richie JP Jr: Status of glutathione and other thiols and disulfides in human plasma. Biochem Pharmacol 60: 19-29, 2000.

27. Karbownik M and Reiter RJ: Antioxidative effects of melatonin in protection against cellular damage caused by ionizing radiation. Proc Soc Exp Biol Med 225: 9-22, 2000.

28. Undeger U, Giray B, Zorlu AF, Oge K and Bacaran N: Protective effects of melatonin on the ionizing radiation induced DNA damage in the rat brain. Exp Toxicol Pathol 55: 379-384, 2004.

29. Taysi S, Koc M, Buyukokuroglu ME, Altinkaynak K and Sahin YN: Melatonin reduces lipid peroxidation and nitric oxide during irradiation-induced oxidative injury in the rat liver. J Pineal Res 34: 173-177, 2003.

30. Tahamtan R, Shabestani Monfared A, Tahamtani Y, Tavassoli A, Akmali M, Mosleh-Shirazi MA, Naghizadeh MM, Ghasemi D, Keshavarz M and Haddadi GH: Radioprotective effect of melatonin on radiation-induced lung injury and lipid peroxidation in rats. Cell J 17: 111-120, 2015.

31. Kaldir M, Cosar-Alas R, Cermik TF, Yurut-Caloglu V, Saynak M, Altaner S, Caloglu M, Kocak Z, Tokatli F, Ture M, et al: Amifostine use in radiation-induced kidney damage. Preclinical evaluation with scintigraphic and histopathologic parameters. Strahlenther Onkol 184: 370-375, 2008.

32. Cosar R, Yurut-Caloglu V, Eskiocak S, Ozen A, Altaner S, Ibis K, Turan N, Denizli B, Uzal C, Saynak M, et al: Radiation-induced chronic oxidative renal damage can be reduced by amifostine. Med Oncol 29: 768-775, 2012.

33. Anwar MM and Moustafa MA: The effect of melatonin on eye lens of rats exposed to ultraviolet radiation. Comp Biochem Physiol C Toxicol Pharmacol 129: 57-63, 2001. 
34. Gibbs FP and Vriend J: The half-life of melatonin elimination from rat plasma. Endocrinology 109: 1796-1798, 1981.

35. Wetterberg L, Eriksson O, Friberg Y and Vangbo B: A simplified radioimmunoassay for melatonin and its application to biological fluids. Preliminary observations on the half-life of plasma melatonin in man. Clin Chim Acta 86: 169-177, 1978.

36. Mihara M and Uchiyama M: Determination of malonaldehyde precursor in tissues by thiobarbituric acid test. Anal Biochem 86 : 271-278, 1978

37. Kucuktulu E, Yavuz AA, Cobanoglu U, Yenilmez E, Eminagaoglu S, Karahan C, Topbas M and Kucuktulu U: Protective effect of melatonin against radiation induced nephrotoxicity in rats. Asian Pac J Cancer Prev 13: 4101-4105, 2012.

38. Cassady JR: Clinical radiation nephropathy. Int J Radiat Oncol Biol Phys 31: 1249-1256, 1995.

39. Kim TH, Freeman CR and Webster JH: The significance of unilateral radiation nephropathy. Int J Radiat Oncol Biol Phys 6: $1567-1571,1980$

40. Prager W and Merkelbach K: Long-term sequelae in the kidneys following abdominal irradiation of advanced malignant ovarian tumors. Radiobiol Radiother (Berl) 27: 341-345, 1986 (In German).

41. Kim BC, Shon BS, Ryoo YW, Kim SP and Lee KS: Melatonin reduces X-ray irradiation-induced oxidative damages in cultured human skin fibroblasts. J Dermatol Sci 26: 194-200, 2001.

42. Vijayalaxmi, Reiter RJ, Herman TS and Meltz ML: Melatonin and radioprotection from genetic damage: In vivo/in vitro studies with human volunteers. Mutat Res 371: 221-228, 1996.

43. Vijayalaxmi, Reiter RJ, Herman TS and Meltz ML: Melatonin reduces gamma radiation-induced primary DNA damage in human blood lymphocytes. Mutat Res 397: 203-208, 1998.

44. Sharma S, Haldar C, Chaube SK, Laxmi T and Singh SS: Long-term melatonin administration attenuates low-LET gamma-radiation-induced lymphatic tissue injury during the reproductively active and inactive phases of Indian palm squirrels (Funambulus pennanti). Br J Radiol 83: 137-151, 2010.

45. Sharma S, Haldar C and Chaube SK: Effect of exogenous melatonin on X-ray induced cellular toxicity in lymphatic tissue of Indian tropical male squirrel, Funambulus pennanti. Int J Radiat Biol 84: 363-374, 2008.
46. Sener G, Jahovic N, Tosun O, Atasoy BM and Yeğen BC: Melatonin ameliorates ionizing radiation-induced oxidative organ damage in rats. Life Sci 74: 563-572, 2003.

47. Karslioglu I, Ertekin MV, Taysi S, Koçer I, Sezen O, Gepdiremen A, Koç M and Bakan N: Radioprotective effects of melatonin on radiation-induced cataract. J Radiat Res (Tokyo) 46: 277-282, 2005.

48. Haddadi G, Shirazi A, Sepehrizadeh Z, Mahdavi SR and Haddadi M: Radioprotective effect of melatonin on the cervical spinal cord in irradiated rats. Cell J 14: 246-253, 2013.

49. Erol FS, Topsakal C, Ozveren MF, Kaplan M, Ilhan N, Ozercan IH and Yildiz OG: Protective effects of melatonin and vitamin $\mathrm{E}$ in brain damage due to gamma radiation: An experimental study. Neurosurg Rev 27: 65-69, 2004.

50. Weiss JF and Landauer MR: Protection against ionizing radiation by antioxidant nutrients and phytochemicals. Toxicology 189: $1-20,2003$

51. Wei H, Zhang X, Wang Y and Lebwohl M: Inhibition of ultraviolet light-induced oxidative events in the skin and internal organs of hairless mice by isoflavone genistein. Cancer Lett 185: 21-29, 2002.

52. Shimoi K, Masuda S, Furugori M, Esaki S and Kinae N: Radioprotective effect of antioxidative flavonoids in gamma-ray irradiated mice. Carcinogenesis 15: 2669-2672, 1994.

53. Anné PR and Curran WJ Jr: A phase II trial of subcutaneous amifostine and radiation therapy in patients with head and neck cancer. Semin Radiat Oncol 12 (Suppl 1): 18-19, 2002.

54. White DC: The histopathologic basis for functional decrements in late radiation injury in diverse organs. Cancer 37 (Suppl 2): 1126-1143, 1976.

55. Williams MV and Denekamp J: Sequential functional testing of radiation-induced renal damage in the mouse. Radiat Res 94: 305-317, 1983.

56. Kim JS, Heo K, Yi JM, Gong EJ, Yang K, Moon C and Kim SH: Genistein mitigates radiation-induced testicular injury. Phytother Res 26: 1119-1125, 2012. 